\title{
Is axonal degeneration a key early event in Parkinson's disease?
}

\section{Authors}

Zuzanna Kurowska ${ }^{a, b}$, Jeffrey H. Kordower ${ }^{c, d}$, A. Jon Stoessl ${ }^{e}$, Robert E. Burke ${ }^{f}$, Patrik Brundin ${ }^{d}$, Zhenyu Yue $^{\mathrm{g}}$, Scott T. Brady ${ }^{\mathrm{h}}$, Jeffrey Milbrandt', Bruce D. Trapp ${ }^{\mathrm{a}, \mathrm{b}}$, Todd B. Sherer', Satish Medicetty ${ }^{\mathrm{b}}$

a. Department of Neurosciences, Lerner Research Institute, 9500 Euclid Avenue, Cleveland, $\mathrm{OH}$ 44195, Cleveland Clinic, Cleveland, OH, USA

b. Renovo Neural Inc., 10000 Cedar Ave, Cleveland, OH 44106, USA

c. Research Center for Brain Repair, Rush University Medical Center, 1735 West Harrison Street, Chicago, IL 60612, USA

d. Van Andel Research Institute, Center for Neurodegenerative Science, 333 Bostwick Ave. N.E., Grand Rapids, MI 49503, USA

e. Pacific Parkinson's Research Centre, Division of Neurology and Djavad Mowafaghian Centre for Brain Health, University of British Columbia and Vancouver Coastal Health, BC, V6T 1Z3, Canada

f. Departments of Neurology and Pathology \& Cell Biology, Columbia University Medical Center, 650 W 168th St, New York City, NY 10032, USA

g. Departments of Neurology and Neuroscience, Friedman Brain Institute, Icahn School of Medicine at Mount Sinai, 1470 Madison Avenue, New York, NY 10029, USA

h. Department of Anatomy and Cell Biology, University of Illinois at Chicago, $808 \mathrm{~S}$. Wood Street, Rm 578, Chicago, IL 60612, USA; Marine Biological Laboratory, 7 MBL Street, Woods Hole, MA 02543, USA

i. Department of Genetics, Washington University School of Medicine in St. Louis, 660 Euclid Avenue, St. Louis, MO 63110, USA; Hope Center for Neurological Disorders, Washington University School of Medicine in St. Louis, 660 Euclid Avenue, St. Louis, MO 63110, USA

j. The Michael J. Fox Foundation for Parkinson's Research. 498 Seventh Avenue, 18th Floor, New York, NY 10018 USA 


\begin{abstract}
Recent research suggests that in Parkinson's disease the long, thin and unmyelinated axons of dopaminergic neurons degenerate early in the disease process. We organized a workshop entitled 'Axonal Pathology in Parkinson's disease', on March 23 ${ }^{\text {rd }}, 2016$, in Cleveland, Ohio with the goals of summarizing the state-of-the-art and defining key gaps in knowledge. A group of eight research leaders discussed new developments in clinical pathology, functional imaging, animal models, and mechanisms of degeneration including neuroinflammation, autophagy and axonal transport deficits. While the workshop focused on PD, comparisons were made to other neurological conditions where axonal degeneration is well recognized.
\end{abstract}

\title{
Main text
}

Around 7 - 10 million people worldwide suffer from Parkinson's disease (PD). PD is usually diagnosed based on motor symptoms (e.g. tremor, slowness of movements, bradykinesia) which are attributed to loss of dopamine in the striatum, as a consequence to degeneration of nigrostriatal dopamine neurons. Devising methods to protect the cell bodies of nigral dopamine neurons has long been a research priority, but emerging knowledge suggests that the research community should shift its focus from the soma to the axonal compartment of dopaminergic neurons.

'I had been sitting on these data for two years before I submitted the paper' - said Dr. Jeffrey Kordower in the first talk of the Workshop, referring to his initial skepticism about the finding published in 2013 that in brains of PD patients, only 3-7 years after the diagnosis the putamen is almost completely depleted of TH-positive axons, while numerous cell bodies in the SNpc remain because the death of these neurons occurs at much slower pace [1]. It is not known if the axons had already degenerated at 3-7 years after diagnosis, or they are still there, just not expressing $\mathrm{TH}$ and other molecules involved in production and maintenance of functional dopaminergic synapses. Unfortunately, it has not been possible to address those questions in post-mortem human brains, as a structural marker specific for dopaminergic axons is not available, and striatum is innervated by axons from multiple nuclei including the cortex, amygdala, and raphe.

Dr. Kordower also highlighted that studies with the growth factors GDNF/neurturin in monkeys and PD patients have suggested that nigrostriatal pathway axons need to be preserved for functional recovery to occur [2,3]. Moreover, the restoration of the nigrostriatal pathway alone is not necessarily translated to functional benefits as formation of synapses with the right target is also required.

Degenerative changes that eventually lead to PD diagnosis start several years before the disease is discovered, and it is possible that loss of synaptic function in dopaminergic neurons is one of the first changes. Dr. Jon Stoessl presented the functional imaging data from PD patients showing evidence for early changes in striatal dopaminergic terminals [4]. The changes in effective dopamine turnover in the caudate and the putamen occurred even in early disease. An increase in dopamine turnover might be a compensatory mechanism that delays onset of clinical symptoms. Changes in dopamine turnover in the putamen precede motor symptom onset substantially, estimated about 8 years prior to onset, and earlier than changes in dopamine synthesis (estimated about 4-6 years prior to onset) $[5,6]$. Indeed, in 
non-manifesting subjects with pathogenic LRRK2 mutations, dopamine turnover is increased many years or even decades prior to expected disease onset [5]. Moreover, young onset PD patients exhibit greater loss of vesicular monoamine transporter (VMAT) compared with onset at older ages, suggesting stronger compensatory mechanisms in the younger brains [6]. This suggests that the eventual onset of motor symptoms in PD reflects a global failure of the compensatory mechanisms in nigrostriatal dopaminergic neurons. It should also be noted that based on PET studies, dopamine transporter binding is reduced by an estimated $56-71 \%$ of control values at symptom onset [7], whereas cell counts are estimated to be reduced by only $31 \%$ in the substantia nigra as a whole, and by $64 \%$ in the ventrolateral substantia nigra [8].

Evidence supporting the notion that initially PD affects synapses and axons, to higher degree than the cell bodies, comes also from pre-clinical research, in particular from some recent genetic rodent PD models. This research was elegantly summarized by Dr. Robert Burke in his talk and recent review [9]. The models that were discussed include: AAV/2 human a-syn-A53T in rat [10], AAV/6 human a-syn-WT in rat [11], hBAC-LRRK2 in mouse [12,13], mBAC-Nurr1(fl/fl)XmBACDAT-CreT2 in mouse [14] and Engrailed1 +/- mouse $[15,16]$, and it is likely that there are other models where such changes are yet to be reported. All of them present some form of axonal abnormalities in TH-positive nigrostriatal fibers before the degenerative processes are detected in the cell bodies. Interestingly, very similar manifestation of early axonopathy is present in all of them: 'swollen' structures called 'spheroids' or 'axonal swellings' appearing in the terminal parts $[10,11,13,15,17]$ or medial forebrain bundle portions of nigrostriatal axons $[12,14,15]$. Similar axonal spheroids were described in the post-mortem brains of PD [18] and Diffuse Lewy Body Disease patients [19], and they are also seen in other neurodegenerative diseases such as multiple sclerosis (MS). In aforementioned rodent models, the axo-degenerative processes are accompanied by other axonal abnormalities that mimic findings made in PD, such as loss of dopaminergic phenotype [11,14,15], changes in levels of axonal transport proteins [10], and autophagy markers [15]. 'It is important to emphasize that although this evidence suggests that axons are the first site of degenerative change, this does not necessarily mean that the primary disturbance at the molecular level first occurs in the axons. For example, a primary disturbance at the nuclear level may result in transcriptional, translational or trafficking abnormalities that first manifest as axonal dysfunction and degeneration. The critical need to focus on axons for both neuroprotective and restorative therapeutics derives not only from their early involvement, but also their essential role in dopamine release in the striatum.' - wrote Dr. Burke and Dr. Tagliaferro in their review [9].

Some of the axonal changes in the Engrailed1 +/- mouse model were described more in depth by Dr. Patrik Brundin. The lack of one Engrailed-1 allele causes slow progressive neurodegeneration of nigrostriatal pathway. The axonal 'swellings' stained by TH, dopamine transporter (DAT) and VMAT appear in the striatum in small numbers as early as 8 days after birth and their size and number increases with age $[15,20]$. A reduction in tissue levels of dopamine in the striatum is not detected until 8 weeks, and it is followed by degeneration of dopaminergic neurons in substantia nigra $[15,16]$. The loss of nigral cell bodies is accompanied by astro- and microgliosis. The nigral neurons that project to the most dorsal striatum also exhibit profound reductions in evoked dopamine release and reuptake. Changes in autophagy pathways have been defined in Engrailed1-deficient mice [15], as well as 
increased sensitivity to oxidative stress [21], abnormalities in mitochondrial function [22] and axonal guidance [23]. All of these features might contribute to the axonal degeneration (see Fig. 1).

The mechanisms of axonal degeneration in PD appear complex and studies in simpler non-vertebrate models might help dissect the underlying chain of molecular events. Dr. Scott Brady presented his research on axonal transport in the isolated axoplasm from the squid giant axon [24,25], as well as his collaboration with Dr. Kordower in mammalian models which found changes in transport motors in PD [26]. The biggest advantage of the squid giant axon model is that it overcomes the complexity of nervous tissue, which makes it difficult to distinguish neuronal microtubules from glial microtubules, and axonal microtubules from dendritic and cell body microtubules. Dr. Brady's findings pinpointing how kinesin and dynein post-translational modifications influence fast axonal transport in the squid giant axons may be informative for further studies in PD models.

Aside from putative impairments of axonal transport, autophagy is another mechanism widely considered to be deficient in PD and other neurodegenerative disorders. Dr. Zhenyu Yue highlighted how disrupted autophagy could interact with axonal degeneration in PD. Specifically, Dr. Yue's suggested that disruptions in the autophagy pathway gene Atg7 may be associated with enhanced levels of endogenous $\alpha$-synuclein and LRRK2 proteins in PD [27].

Many mechanisms of the axonal degeneration processes that are suggested to be active in PD were first mapped out in the peripheral nervous system studies. Dr. Milbrandt summarized the findings of Wallerian degeneration studies and presented newly identified actors such as specific SARM1 and MAP kinases and the NAD+ synthetic enzyme NMNAT2. New studies reveal that these pathways cooperate in a locally mediated axon destruction program, with NAD+ metabolism playing a central role $[28,29]$.

In the final talk of the Workshop, Dr. Bruce Trapp described axonal pathology in MS. While MS is an inflammatory demyelinating disease, it is now accepted that permanent neurological disability is caused by axonal and neuronal degeneration [30]. Axons become transected during immune-mediated demyelination [31] and chronically demyelinated axons degenerate due to loss of trophic support derived from myelin and oligodendrocytes [30]. Dr. Trapp highlighted that MS patients are diagnosed early in the disease. This allows delivery of experimental neuroprotective therapies at a time when therapeutic targets are abundant. This stands in contrast to PD where the disease process is presumably advanced before diagnosis is made. Novel therapeutics that limit or reverse axonal and neuronal degeneration in MS might benefit PD patients as molecular cascades involved in axonal degeneration are likely to be shared between these two diseases.

'This workshop can be seen as a statement that we, as scientific investigators, need to take a harder look at the axons in PD. What will be more important, however, is how we will use the information. Ultimately, we would want to point at diagnostic marker, and find therapeutics related to axonal degeneration processes, and eventually target those processes to prevent PD' - concluded Dr. Todd Sherer the Chief Executive Officer of The Michael J. Fox Foundation for Parkinson's Research (MJFF). 


\section{Table 1.}

Critical research questions

- Is axonal degeneration limited to nigral dopaminergic neurons in PD?

- How does alpha-synuclein influence axonal degeneration?

- How relevant are the animal models of PD that exhibit axonal degeneration?

- What are the molecular targets for inhibition of axonal degeneration in PD?

\section{Figure 1.}
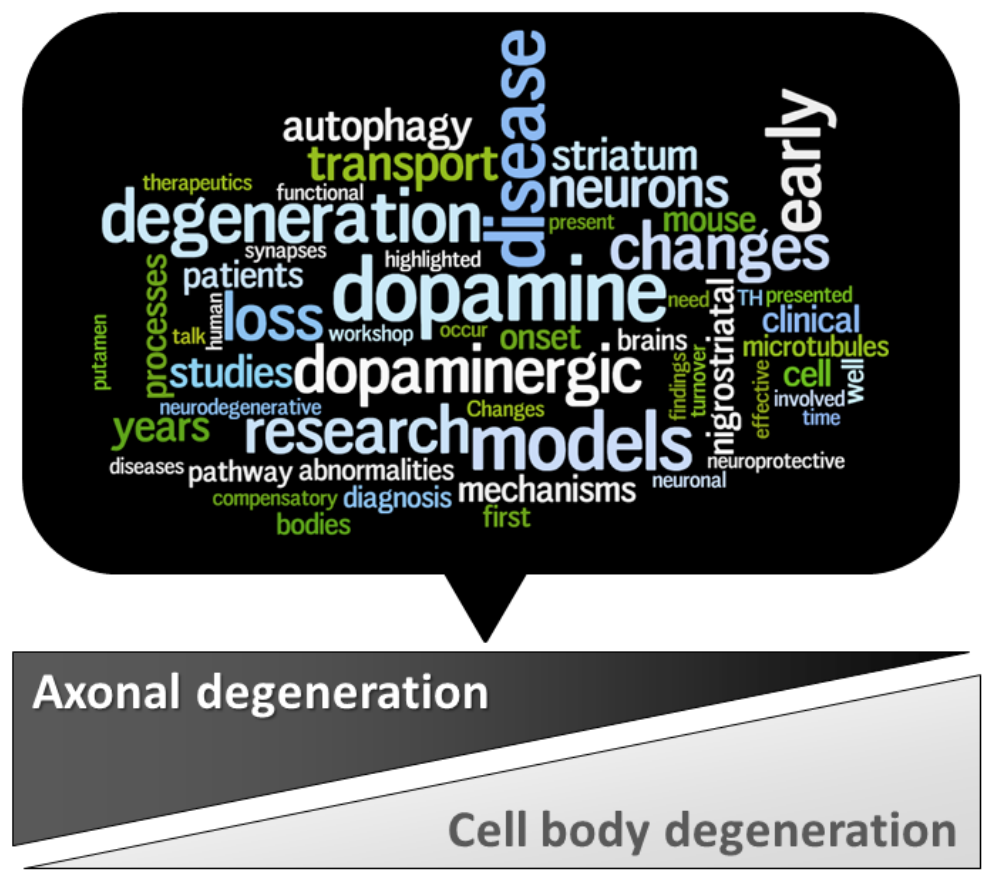

Time from initial disease trigger

Figure 1. The word cloud was based on this text and presents axonal degeneration mechanisms in PD discussed here. We believe that axonal degeneration starts long before cell bodies in substantia nigra are affected, and long before PD is diagnosed.

\section{Acknowledgement}

The Workshop program and the list of speakers can be found at:

http://www.renovoneural.com/wp-content/uploads/2011/11/PD-Workshop Program Final.pdf 


\section{Conflict of interest statement}

Patrik Brundin is scientific advisor to Renovo Neural Inc. Zuzanna Kurowska is affiliated with Renovo Neural Inc. as an Associate Scientist. Satish Medicetty is CEO of Renovo Neural Inc. Bruce Trapp is founder of Renovo Neural Inc. The other authors declare no potential conflict of interest.

\section{References}

[1] Kordower JH, Olanow CW, Dodiya HB, Chu Y, Beach TG, Adler CH, Halliday GM, Bartus RT (2013) Disease duration and the integrity of the nigrostriatal system in Parkinson's disease. Brain 136, 24192431.

[2] Bartus RT, Herzog CD, Chu Y, Wilson A, Brown L, Siffert J, Johnson EM, Olanow CW, Mufson EJ, Kordower JH (2011) Bioactivity of AAV2-neurturin gene therapy (CERE-120): differences between Parkinson's disease and nonhuman primate brains. Mov. Disord. 26, 27-36.

[3] Kirik D, Rosenblad C, Björklund A (2000) Preservation of a functional nigrostriatal dopamine pathway by GDNF in the intrastriatal 6-OHDA lesion model depends on the site of administration of the trophic factor. Eur. J. Neurosci. 12, 3871-3882.

[4] Sossi V, de la Fuente-Fernández R, Holden JE, Schulzer M, Ruth TJ, Stoessl J (2004) Changes of dopamine turnover in the progression of Parkinson's disease as measured by positron emission tomography: their relation to disease-compensatory mechanisms. J. Cereb. Blood Flow Metab. 24, 869876.

[5] Sossi V, de la Fuente-Fernández R, Nandhagopal R, Schulzer M, McKenzie J, Ruth TJ, Aasly JO, Farrer MJ, Wszolek ZK, StoessI JA (2010) Dopamine turnover increases in asymptomatic LRRK2 mutations carriers. Mov. Disord. 25, 2717-2723.

[6] de la Fuente-Fernández R, Schulzer M, Kuramoto L, Cragg J, Ramachandiran N, Au WL, Mak E, McKenzie J, McCormick S, Sossi V, Ruth TJ, Lee CS, Calne DB, Stoessl AJ (2011) Age-specific progression of nigrostriatal dysfunction in Parkinson's disease. Ann. Neurol. 69, 803-810.

[7] Lee CS, Samii A, Sossi V, Ruth TJ, Schulzer M, Holden JE, Wudel J, Pal PK, de la Fuente-Fernandez R, Calne DB, Stoessl AJ (2000) In vivo positron emission tomographic evidence for compensatory changes in presynaptic dopaminergic nerve terminals in Parkinson's disease. Ann. Neurol. 47, 493-503.

[8] Fearnley JM, Lees AJ (1991) Ageing and Parkinson's disease: substantia nigra regional selectivity. Brain 114 ( Pt 5), 2283-2301.

[9] Tagliaferro P, Burke RE (2016) Retrograde Axonal Degeneration in Parkinson Disease. J Parkinsons Dis 6, 1-15. 
[10] Chung CY, Koprich JB, Siddiqi H, Isacson O (2009) Dynamic changes in presynaptic and axonal transport proteins combined with striatal neuroinflammation precede dopaminergic neuronal loss in a rat model of AAV alpha-synucleinopathy. J. Neurosci. 29, 3365-3373.

[11] Decressac M, Mattsson B, Lundblad M, Weikop P, Björklund A (2012) Progressive neurodegenerative and behavioural changes induced by AAV-mediated overexpression of $\alpha$-synuclein in midbrain dopamine neurons. Neurobiol. Dis. 45, 939-953.

[12] Tagliaferro P, Kareva T, Oo TF, Yarygina O, Kholodilov N, Burke RE (2015) An early axonopathy in a hLRRK2(R1441G) transgenic model of Parkinson disease. Neurobiol. Dis. 82, 359-371.

[13] Li Y, Liu W, Oo TF, Wang L, Tang Y, Jackson-Lewis V, Zhou C, Geghman K, Bogdanov M, Przedborski S, Beal MF, Burke RE, Li C (2009) Mutant LRRK2(R1441G) BAC transgenic mice recapitulate cardinal features of Parkinson's disease. Nat. Neurosci. 12, 826-828.

[14] Kadkhodaei B, Alvarsson A, Schintu N, Ramsköld D, Volakakis N, Joodmardi E, Yoshitake T, Kehr J, Decressac M, Björklund A, Sandberg R, Svenningsson P, Perlmann T (2013) Transcription factor Nurr1 maintains fiber integrity and nuclear-encoded mitochondrial gene expression in dopamine neurons.

Proc. Natl. Acad. Sci. U.S.A. 110, 2360-2365.

[15] Nordström U, Beauvais G, Ghosh A, Pulikkaparambil Sasidharan BC, Lundblad M, Fuchs J, Joshi RL, Lipton JW, Roholt A, Medicetty S, Feinstein TN, Steiner JA, Escobar Galvis ML, Prochiantz A, Brundin $P$ (2015) Progressive nigrostriatal terminal dysfunction and degeneration in the engrailed 1 heterozygous mouse model of Parkinson's disease. Neurobiol. Dis. 73, 70-82.

[16] Sonnier L, Le Pen G, Hartmann A, Bizot J-C, Trovero F, Krebs M-O, Prochiantz A (2007) Progressive loss of dopaminergic neurons in the ventral midbrain of adult mice heterozygote for Engrailed1. J. Neurosci. 27, 1063-1071.

[17] Laguna A, Schintu N, Nobre A, Alvarsson A, Volakakis N, Jacobsen JK, Gómez-Galán M, Sopova E, Joodmardi E, Yoshitake T, Deng Q, Kehr J, Ericson J, Svenningsson P, Shupliakov O, Perlmann T (2015) Dopaminergic control of autophagic-lysosomal function implicates $\mathrm{Lm} \times 1 \mathrm{~b}$ in Parkinson's disease. Nat. Neurosci. 18, 826-835.

[18] Galvin JE, Uryu K, Lee VM, Trojanowski JQ (1999) Axon pathology in Parkinson's disease and Lewy body dementia hippocampus contains alpha-, beta-, and gamma-synuclein. Proc. Natl. Acad. Sci. U.S.A. 96, 13450-13455.

[19] Duda JE, Giasson BI, Mabon ME, Lee VM-Y, Trojanowski JQ (2002) Novel antibodies to synuclein show abundant striatal pathology in Lewy body diseases. Ann. Neurol. 52, 205-210.

[20] Kurowska Z, Kidd G, Benson E, Brundin P, Medicetty S, Trapp B (2015) 3D-EM characterization of "axonal swellings" in the Engrailed-1 heterozygous mouse model of Parkinson's disease. In Movement Disorders Suppl. 1 (poster), San Diego, p. 1:94. 
[21] Rekaik H, Blaudin de Thé F-X, Fuchs J, Massiani-Beaudoin O, Prochiantz A, Joshi RL (2015) Engrailed Homeoprotein Protects Mesencephalic Dopaminergic Neurons from Oxidative Stress. Cell Rep 13, 242-250.

[22] Alvarez-Fischer D, Fuchs J, Castagner F, Stettler O, Massiani-Beaudoin O, Moya KL, Bouillot C, Oertel WH, Lombès A, Faigle W, Joshi RL, Hartmann A, Prochiantz A (2011) Engrailed protects mouse midbrain dopaminergic neurons against mitochondrial complex I insults. Nat. Neurosci. 14, 1260-1266.

[23] Stettler O, Joshi RL, Wizenmann A, Reingruber J, Holcman D, Bouillot C, Castagner F, Prochiantz A, Moya KL (2012) Engrailed homeoprotein recruits the adenosine A1 receptor to potentiate ephrin A5 function in retinal growth cones. Development 139, 215-224.

[24] Morfini G, Pigino G, Opalach K, Serulle Y, Moreira JE, Sugimori M, Llinás RR, Brady ST (2007) 1Methyl-4-phenylpyridinium affects fast axonal transport by activation of caspase and protein kinase $C$. Proc. Natl. Acad. Sci. U.S.A. 104, 2442-2447.

[25] Serulle Y, Morfini G, Pigino G, Moreira JE, Sugimori M, Brady ST, Llinás RR (2007) 1-Methyl-4phenylpyridinium induces synaptic dysfunction through a pathway involving caspase and PKCdelta enzymatic activities. Proc. Natl. Acad. Sci. U.S.A. 104, 2437-2441.

[26] Chu Y, Morfini GA, Langhamer LB, He Y, Brady ST, Kordower JH (2012) Alterations in axonal transport motor proteins in sporadic and experimental Parkinson's disease. Brain 135, 2058-2073.

[27] Friedman LG, Lachenmayer ML, Wang J, He L, Poulose SM, Komatsu M, Holstein GR, Yue Z (2012) Disrupted autophagy leads to dopaminergic axon and dendrite degeneration and promotes presynaptic accumulation of $\alpha$-synuclein and LRRK2 in the brain. J. Neurosci. 32, 7585-7593.

[28] Gerdts J, Summers DW, Milbrandt J, DiAntonio A (2016) Axon Self-Destruction: New Links among SARM1, MAPKs, and NAD+ Metabolism. Neuron 89, 449-460.

[29] Gerdts J, Brace EJ, Sasaki Y, DiAntonio A, Milbrandt J (2015) SARM1 activation triggers axon degeneration locally via NAD ${ }^{+}$destruction. Science 348, 453-457.

[30] Trapp BD, Nave K-A (2008) Multiple sclerosis: an immune or neurodegenerative disorder? Annu. Rev. Neurosci. 31, 247-269.

[31] Trapp BD, Peterson J, Ransohoff RM, Rudick R, Mörk S, Bö L (1998) Axonal transection in the lesions of multiple sclerosis. N. Engl. J. Med. 338, 278-285. 